\title{
VII Sección
}

\section{Arte y literatura}

\section{La poética de lo abigarrado en La orquesta de cristal de Enrique Lihn}

\author{
Daniel Rojas Pachas \\ Universidad de Guanajuato, México \\ df.rojaspachas@ugto.mx \\ https://orcid.org/0000-0002-3819-2357
}

Recibido: 20 de abril de 2020

Aceptado: 19 de mayo de 2020

Resumen: La presente lectura de La orquesta de cristal (1976) se enfoca en caracterizar la poética de lo abigarrado y sus recursos. La hiperretórica, el kitsch y el humor conceptual son estrategias textuales que dan cuenta del carácter transgresor y exploratorio de la trilogía de novelas que Enrique Lihn dedicó a la retórica del poder. La voz narrativa del chileno expone una sensibilidad caracterizada por lo amontonado e inarmónico, una multiplicidad de colores y materiales heterogéneos unidos sin concierto. Linn construye un habla marcada por la violencia política, la censura y autocensura. En la novela, el autor parodia no sólo a políticos y figuras de autoridad, sino también al campo cultural del momento y su seudo arte. Este trabajo expone una narrativa experimental y polifónica, capaz de generar atmósferas en que el detritus aparece como la máxima realización del intelecto latinoamericano, al ser sometido por la dictadura y un público adiestrado por monumentos al mal gusto.

Palabras clave: abigarramiento; kitsch; humor conceptual; hiperretórica; Enrique Lihn; novela latinoamericana.

\section{The poetics of abigarrated in La orquesta de cristal of Enrique Lihn}

\section{(๑) $\Theta \odot$}

La Revista Estudios es editada por la Universidad de Costa Rica y se distribuye bajo una Licencia Creative Commons Atribución-NoComercial-CompartirIgual 3.0 Costa Rica. Para más información envíe un mensaje a 
Abstract: The present reading of The Crystal Orchestra (1976) focuses on characterizing the poetics of the abigarrated and its resources. The hyperrethoric, the kitsch and the conceptual humor are textual strategies that show the transgressive and exploratory character of the trilogy of novels that Enrique Lihn dedicated to the rhetoric of power. The narrative voice of Lihn exhibits a sensitivity characterized by the piled up and inharmonic, a multiplicity of colors and heterogeneous materials united without concert. Linn builds a speech marked by political violence, censorship and self-censorship. In the novel, the author parodies not only politicians and authority figures, but also the cultural field of the moment and its pseudo art. This work exposes an experimental and polyphonic narrative, capable of generating atmospheres in which the detritus appears as the maximum realization of the Latin American intellect once this was dominated by the dictatorship and a public trained by monuments to bad taste.

Keywords: variegation; kitsch; conceptual humor; hyperrethoric; Enrique Lihn; latin american novel

\section{Introducción}

Enrique Lihn declara que su proyecto narrativo, por su carácter contracultural y por estar de espaldas a las expectativas del lector de novelas de esa época, es un "suicidio temporal de su imagen de autor" (Lihn, 1996, p. 576). En su texto "Literatura y Dictadura" agrega una distinción clara entre la producción textual del exilio y la literatura del insilio, o sea caracteriza la tarea de escribir en un marco de censura y autocensura, propio de un campo cultural adverso. "Los exiliados no han tenido que responder con sus obras a la pregunta siguiente: ¿Cómo verbalizar un discurso que está prohibido?" (Lihn, 1996, p. 495). Para Enrique Lihn, la novela es un laboratorio que le permite investigar las deformaciones del lenguaje y realizar un estudio de teratología, destinado a diseccionar las monstruosidades que habitan la sociedad chilena y continental.

El chileno concibe sus novelas como un despliegue de cháchara. La impostura de simulacros retóricos, al interior de sus textos, se traduce en la puesta en escena

\section{(C) $(0 \bigcirc)$}

La Revista Estudios es editada por la Universidad de Costa Rica y se distribuye bajo una Licencia Creative Commons Atribución-NoComercial-CompartirIgual 3.0 Costa Rica. Para más información envíe un mensaje a 
de un disfraz de histrión que le sirve para parodiar al dictador y a todo relato represivo que se pretende inscribir como centro de una comunidad.

La retórica ideológica o cháchara fuerza a los sujetos a sumirse en formas mecánicas de expresión y repeticiones de ideas preconcebidas. Estamos ante contenidos convencionales que el habla del poder impone a la comunidad, haciéndola consumidora y cómplice del horror dictatorial.

El poder es una perversión personal que se presenta como una salvación colectiva. Y los sujetos abrumados por el poder tienen que hacer una ficción homóloga. En el arte... los tipos están constantemente adulando a un poder que los está anulando. El sujeto que se acerca al poder para adularlo, como en un acto mimético, exagera el lenguaje del poder y, al exagerarlo de alguna manera lo denuncia (Lihn citado en Foxley, 1988, p. 4).

En ese sentido, Gerardo de Pompier es la máscara ideológica y lingüística que se alza como la máxima realización de lo que las novelas de Lihn buscan representar, actos fallidos como una orquesta invisible e inaudible, en torno a la cual orbitan múltiples formas de enmascarar la verdad. Paradójicamente, el histrión, al hacer mímesis del habla del poder, desestabiliza y desenmascara el vacío tras la retórica ideológica. Gerardo de Pompier encarna la censura, el silenciamiento y los múltiples rostros de un lenguaje corrupto.

La orquesta de cristal publicada por la Editorial Sudamericana (1976) y reeditada por Hueders (2013) es la segunda novela de Lihn. Este texto cuenta con una estructura circular de textos que se yuxtaponen a propósito de un objeto cuasi inexistente o un acto fallido: the crystal orchestra, una extravagante empresa creada por el filántropo Charles Royce a fines del siglo XIX en París.

Rodrigo Cánovas (1986) caracteriza la estructura de la novela de la siguiente forma: "La orquesta de cristal diagrama una espiral: en su centro, está la orquesta y alrededor, las distintas versiones escriturales de sus actuaciones. Existe una analogía proporcional entre ese centro musical y sus letras periféricas: Los dos significan la carencia" (p. 51).

\section{(๑) $\odot \odot$}

La Revista Estudios es editada por la Universidad de Costa Rica y se distribuye bajo una Licencia Creative Commons Atribución-NoComercial-CompartirIgual 3.0 Costa Rica. Para más información envíe un mensaje a 
Las crónicas que componen la novela y que se suceden por más de setenta y cinco años, nos presentan el devenir de una orquesta invisible hecha de cristal e inaudible, pues los instrumentos se destruyen a la primera nota que tocan. La estructura discursiva de la obra se encuentra repleta de citas a pie de página y referencias cruzadas que remiten al formato de ensayo académico.

La obra a nivel temático presenta como leitmotiv el discurso legitimador de la crítica con respecto a las bellas artes y su valoración en la sociedad en términos de prestigio y autoridad. Se trata de documentación que se autorrefiere y copia a sí misma sin escrúpulos, al punto que el contenido medular del discurso pasa a un segundo plano. Esta novela encarna el triunfo de la "cháchara" y muestra de qué manera las ideologías y los discursos terminan por aplastar la realidad validando incluso hechos $u$ objetos inexistentes. Una hiperrealidad cuyo soporte es el arte de la palabra, al cual Linn define como:

Retoricismo consagrado a disociar la palabra de los hechos y de las cosas y a convencernos de que lo negro es blanco y viceversa, a través de profusos discursos ornamentales; el vacío o la insuficiencia de nuestra realidad en contraposición a la pomposidad con que la inventariamos en el lenguaje, deformándola para constituirla en una plenitud (Lihn citado en Libertella, 1990, p. 48).

Partiendo de un argumento tal, me propongo en este artículo demostrar el modo en que Lihn utiliza la poética del abigarramiento y ciertas estrategias textuales, tales como la hiperretórica, el kitsch y el humor conceptual, a fin de enmascarar las problemáticas sobre el poder que desea representar, a saber: los simulacros culturales y la palabra legitimadora en el marco de la dictadura en Chile.

Los cronistas de La orquesta de cristal yuxtaponen géneros menores de la belle époque: folletín, poesía en prosa, diario de vida, entre otras formas. La narración privilegia los lugares comunes, propios de los estilos de moda. En cuanto a las voces que encontramos al interior de La orquesta de cristal, estas ocupan como disfraz el galicismo mental y el saber europeo. Esta identidad desfasada, propia del artista monigote o mercenario que vende sus letras al poder, se instala acorde a los 
gustos de su tiempo y al oficialismo imperante. A juicio de Lihn, este sentir continúa impregnando nuestra lengua y estética y esto no sólo remite a una tradición de poetas y novelistas, cronistas y pensadores que llegaron a ser imitados, sino también al rol que compete a la academia y a la crítica latinoamericana.

Gerardo de Pompier al ostentar una retórica que emula el modernismo y en especial los galicismos mentales de la llamada belle époque, no sólo opera como una careta, que extrema una estética visual y porte, es también un símbolo de la continua metamorfosis que en nuestra sociedad asume el bastardaje cultural, que se adapta a la última moda prestigiada. En el caso de los intelectuales y artistas, estos adhieren al último movimiento o -ismo en boga. Pompier es "una parodia del Modernismo como origen de nuestra identidad literaria y cultural puesto que lo actualiza y lo asume "piadosamente" (Lihn, 1996, p. 590).

El kitsch es usado en la novela para edificar un cuadro fantasmático del París del cruce de siglos. La Casa de los Cuatro Vientos se presenta como un palacete que sirve de sede a la Fundación $\mathrm{X}$, una institución encargada de sostener el ostentoso simulacro de una orquesta fantasma por medio de beneficios pecuniarios otorgados a los intelectuales adeptos de la entidad y sus proyectos. Por último, el humor conceptual es un recurso esencial de la obra, pues a través de la parodia y recursos metalépticos, el texto pone en evidencia el carácter de artificio de su propia novela y la tradición en la cual se enmarca su publicación.

Lihn en lugar de callar y generar obras complacientes con el poder o en contra parte, publicar textos panfletarios tomando el lugar de las víctimas y los silenciados como divisa de lucha, el autor satura la maquinaria comunicativa y la hace chirriar con un caudal discursivo de palabrería impotente.

\section{Hiperretórica como enmascaramiento: galicismos mentales}

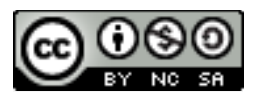

La Revista Estudios es editada por la Universidad de Costa Rica y se distribuye bajo una Licencia Creative Commons Atribución-NoComercial-CompartirIgual 3.0 Costa Rica. Para más información envíe un mensaje a revistaestudios.eeg@ucr.ac.cr. 
Enrique Linn, al definir sus novelas y los procesos técnicos detrás de ellas, señala que estamos ante un: "libro heterogéneo (de relaciones abigarradas o múltiples con otras escrituras, en el sentido derridiano de la palabra escritura)" (Lihn, 1996, p. 587). Respecto a las relaciones abigarradas que Lihn alude en la cita, puedo señalar que los signos múltiples que pueblan estos textos, se autorrefieren como en una cinta de Moebius, mostrando el encadenamiento artificial de los significados o el ejercicio reflejo de la metarrepresentación.

Las tres novelas de Lihn presentan estructuras peculiares y bien diferenciadas, que las configuran como textos híbridos e intermediales. Con esto, el autor busca a través de sus narraciones indagar en los absolutismos, formas de entender y representar el mundo con la correspondiente versión de la realidad que generan. El autor analiza la precariedad de movimientos como el naturalismo, el decadentismo, los simbolistas, el surrealismo y desde luego el modernismo.

Estas estéticas e ideologías postularon una cosmovisión con sus respectivos estereotipos, axiomas, debates, tipos humanos y tópicos, para terminar, convertidos en material de desecho. En palabras de Lihn, el lenguaje reconoce "su carácter de cosa hechiza, artificial, prefabricada: hablamos y escribimos siempre de una manera estereotipada" (Lihn citado en Lastra, 1980, p. 68). El autor parodia a la sociedad chilena y sus conflictos políticos y sociales en los años setenta y los viste con un ropaje decimonónico. El autor prioriza: "la destrucción de las retóricas a través de una hiperretórica, el hacer funcionar elementos de otras literaturas de una manera distinta, la crítica del lenguaje" (Lihn citado en Lastra, 1980, p. 146).

La acción de la novela se inicia en la década del setenta con una misma cita repetida — hasta el hartazgo - por los cronistas. Esta suerte de umbral sirve para comprender la naturaleza elusiva del objeto sobre el cual versan los múltiples documentos glosados por el narrador principal, esa voz fantasmal encargada de compilar todo lo dicho sobre la orquesta, a petición de la Fundación X:

Todos los elementos de esta orquesta —primero y único ejemplar en su género—son obras maestras de la cristalería: un conjunto de preciosos objetos de por sí sonoros que, desde la relativa e inevitable opacidad de los "bronces", hasta la invisibilidad, o

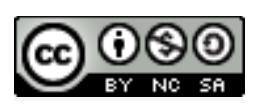

La Revista Estudios es editada por la Universidad de Costa Rica y se distribuye bajo una Licencia Creative Commons Atribución-NoComercial-CompartirIgual 3.0 Costa Rica. Para más información envíe un mensaje a revistaestudios.eeg@ucr.ac.cr. 
cuasi, de los instrumentos de aliento, cubren la gama entera de la transparencia, cualidad seductora por antonomasia (Lihn, 2013, p. 17).

Pompier representa el histrión, el sujeto desfasado cuya personalidad se acomoda ante el poder, gracias a un arsenal retórico muy particular. Este dandi no sólo contribuye a la atmósfera de la obra, sino que es la figura central que encarna la poética de lo abigarrado y a partir de la cual los demás cronistas se suman con desparpajo a la yuxtaposición de textos y discursos, para así reflejar esa hiperrealidad sostenida en torno a la "cháchara".

Los cronistas de La orquesta de cristal son sujetos oportunistas que buscan la protección del orden establecido, en esa medida encarnan una voz muda abierta a ser todas las voces, esto los hace proclives a las condiciones de la época en que se instalan para subsistir como sujetos transhistóricos y errantes.

Tan pronto habla como es hablado, haciendo uso en ambos casos de la misma retórica, la cual se otorga así, y a partir de esa reversibilidad irresponsable, la dudosa libertad de adoptar cualquier punto de vista y ninguno en particular. Por donde pasa Pompier no vuelve a crecer la responsabilidad del discurso (Lihn, 1980, p. 353).

Gerard de Pompier en calidad de cronista contribuye con textos referidos a la puesta en escena de la orquesta, mientras que en las notas explicativas a la novela introduce fragmentos de su diario íntimo, en el cual expone sus postulados respecto a la religiosidad del arte. Además, a través de un libelo procede como defensor de su amigo, el intelectual Roberto Albornoz (espeleólogo), con quien, de acuerdo a la historia, asistió en 1900 a la primera presentación de la orquesta en la Feria de las Artes y la Industria en París. Pompier y Albornoz son histriones que delatan el actuar del intelectual hispanoamericano amparado en el oficialismo.

El género principal y que cumple la función de marco de la obra es la monografía. La novela sepulta al lector con una glosa que recopila todo lo que se ha dicho respecto a la orquesta de cristal en un periodo de 75 años. La variación entre las declaraciones es mínima, de manera que la autoría y habla individual se funde en

\section{(C) $(\Theta \odot \odot$}

La Revista Estudios es editada por la Universidad de Costa Rica y se distribuye bajo una Licencia Creative Commons Atribución-NoComercial-CompartirIgual 3.0 Costa Rica. Para más información envíe un mensaje a 
un gran pastiche. Héctor Libertella en Las sagradas escrituras llama la atención acerca de las pugnas retóricas sobre las que se asienta el texto: "El cronista se funde entonces con la manera de decir de esos cronistas y ya no busca distinguir su voz, de modo que aparece como cierta voluntad de dispersarse silenciosa, discretamente, en unas retóricas que se enfrentan entre ellas y hablan" (Libertella, 1993, p. 172). En este sentido, cabe recordar una conferencia dictada por el propio Lihn titulada "Doce años de escritura en todos los géneros" (1985, en el Instituto Chileno-Alemán de Cultura de la Ciudad de Concepción) en la que cuenta la génesis de su novela a partir de su contacto con archivos de la Escuela de Bellas Artes y su voluntad de utilizarlos como material ficcional:

Esa cosa defensiva y temerosa que se da con signo menos o con signo más en la escritura, porque siempre uno está también citando o re-citando u organizando un material previo, pre constituido; pero que en este caso era simplemente inercia y temor frente a aquello de lo que se está hablando o, quizás, también desidia, pereza y otras cosas así (Lihn, 2011, p. 190).

La supuesta monografía dedicada a the crystal orchestra se erige sobre una gran cantidad de citas, mecanismo por el cual ingresan a la dinámica novelística diversos registros que contribuyen a encubrir y ornamentar el acto fallido que las inspira (la orquesta inaudible). Los autores son presentados a través del estilo directo: "Schopenhauer, Wagner, Catulle Mendes — se exalta Roberto Albornoz en su estilo juvenil, para el Mercurio de Valparaíso-" (Lihn, 2013, p. 20).

Estos mecanismos se complejizan al difuminarse la enunciación del narrador principal. Cuando el narrador pierde el control de las citas comienza una serie de plagios o parafraseo sutil que contribuye a construir una voz colectiva. Un yo enmascarado domina la novela y sirve como un espacio que puede ser apropiado por el cronista de turno, de modo que las voces se van alternando sin orden o armonía.

La obra utiliza otro elemento de la monografía académica: el sistema de notas a pie de página o notas complementarias al discurso principal. Como elemento 
paratextual, estas referencias contribuyen al abigarramiento del tema central y agregan información enciclopédica en torno a lo que refiere la diégesis. El origen de the crystal orchestra y la historia de su promotor, el misterioso Charles Royce, se presentan en el apéndice de la novela, pues en la diégesis el fundador de la orquesta es referido tan sólo como Mr. X.

Mr. X. eligió notoriamente el mismo momento en que la ciudad augusta, capital de la cultura, hacía resonar armoniosamente en la concavidad de su copa de oro los truenos de la industria y las voces dulcísimas del arte, en una fiesta de la unión subyacente de los contrarios, para ofrecer, por su parte, en esa especie de clandestinidad propia de las ceremonias iniciáticas, el resultado de su esfuerzo sublime: The Crystal Orchestra (Lihn, 2013, pp. 24-25).

Lo que aúna a todas las voces, formatos y textos que cruzan la novela es que cada uno desde su particular interés y beneficio se refieren a todo lo que circunda la orquesta, a fin de eludir su música inaudible y algo que a todas luces salta a la vista, la imposibilidad de reconocer los instrumentos transparentes. A fin de no quedar como ignorantes o, como dice Lihn, debido a un "mecanismo defensivo" (Lihn, 2011, p. 190), los cronistas se limitan a citar ad aeternum, sin dar cuenta de la fuente. Todo este andamiaje retórico va en una sola dirección: dar rodeos para evitar hablar de lo que no se puede ni ver ni oír:

Y no es raro que musicólogos y críticos de nota prefieran distraer sus observaciones técnicas, ante el temor de confundir violas con violines o un oboe con una cornamusa, abordando temas de interés general: los nuevos caminos y las personalidades que representan, por ejemplo, la clave del complejo dibujo de la música contemporánea en los cuatro continentes (Lihn, 2013, p. 17).

Los cronistas recurren a la opacidad del signo y a la cita culta, para ocultar su ineptitud y falta de talento, por ello Lihn mismo sostendrá que "la novela estudia la palabra como modo de crear realidades sustitutivas que sólo existen en el lenguaje" (Lihn citado en Gómez, 1981, p. 6). En suma, en La orquesta de cristal los cronistas/copistas despliegan de modo alternativo su "cháchara", distinguiéndose 
más que por su personalidad (sus actos y atributos dentro de la realidad), por una serie de signos y códigos que se repiten de forma mecánica en el papel. La obra se construye a partir de un sujeto colectivo cuyos fines, según Lihn, son:

Realizar la práctica de la monstruosidad de un discurso neurótico colectivo — sociótico- como el medio de revelarlo, formalizándolo. De ponerlo en evidencia... Yo mismo quise desplegar y encarnar, por la vía de la materialización de ese fantasma, la sociosis propia de nuestro discurso y decurso histórico a través de un narrador que no dice, por sí mismo, nada y que hace hablar, en cambio, como copista, una sería de discursos vacíos (Lihn citado en Libertella, 1990, p. 89).

La orquesta de cristal pone en el centro de la discusión el problema de la censura y también la apropiación de los conocimientos, ideologías, movimientos y cosmovisiones que son reutilizados por la autoridad de turno, para construir una versión de la realidad.

El silencio y la "cháchara" están imbricados, pues la "cháchara" en calidad de discurso vacío del poder oculta, borra, higieniza, adoctrina y sume en el silencio una cantidad de historias y testimonios. En la novela, la represión opera mecánicamente, a través de los múltiples documentos que legitiman un acto fallido (que no se verifica). Se nos comunica la historia de la sinfonía que nadie escuchó, pero de la cual todos dicen algo.

La intervención del nazismo, que termina por destruir el objeto, hace real la extinción de una orquesta que jamás fue escuchada, sin embargo, los discursos esgrimidos siguen en funcionamiento hasta el presente, mediante la novela que tenemos en nuestras manos. La nota 59 de La orquesta de cristal da cuenta de la naturaleza cómplice del texto como extensión del simulacro:

Por alguna razón —no somos los últimos en dar fe de ella-, en cambio, La Orquesta de Cristal, en su última o primera edición, aparece firmada por un nombre -Enrique Lihn - respecto del cual el de Heinrich de Linderhöfer resulta ser [...] [e]l mismo individuo (nosotros) que escribió, en una época indeterminada y desde un lugar incierto, el preludio o la obertura de La Orquesta de Cristal, ¿no sé el mismo que se finge otro, Heinrich vön Linderhöfer, para engañar a los lectores? (Lihn, 2013, p. 169).

\section{(ब) $(\Theta \odot$}

La Revista Estudios es editada por la Universidad de Costa Rica y se distribuye bajo una Licencia Creative Commons Atribución-NoComercial-CompartirIgual 3.0 Costa Rica. Para más información envíe un mensaje a 
En cuanto a los cronistas de la obra, que también podemos denominar copistas, éstos ocupan alternativamente la primera persona para exponer sus ideas. El yo se presenta como una categoría vacía y evanescente que es asumida como un traje. Así, se revela que el yo es un objeto parlante compuesto por una multiplicidad de discursos propios y ajenos que se superponen. Las subjetividades se configuran en consonancia con el poder y su mudez verbalizadora. El yo se vuelve un disfraz, como Pompier, que asume el habla de una época, su espíritu y sus reglas. Lihn señala que parte de la literatura escrita en los años de dictadura en Chile, ha operado bajo la misma mecánica. En cuanto a la novela, el autor cuestiona el género y a sus pares por edificar una escritura al servicio de una verdad, la cual trabaja bajo lineamientos del mercado y una crítica legitimadora de simulacros culturales.

Estoy pensando de qué manera la novela, por el hecho de presumir el ser reveladora respecto de la realidad y tener una relación directa e inmediata con la verdad, se apropia de todos los demás géneros y formas literarias, los intriga y se beneficia de ellos, para construir su gran palacete, su gran industria, su statu quo. Para mí eso es algo contra lo que me resisto: la mía es una resistencia de "lumpen" o de "marginal". A ese palacete yo quiero tirarle unas piedras y quebrarle los vidrios (Lihn citado en Coddou, 1978, pp. 149-150).

La obra insiste en reafirmar la inexistencia del objeto que motiva su escritura. El sujeto que habla también es puesto en crisis, pues los discursos se esconden a través de un yo colectivo que va alternándose de manera errática. Los cronistas implicados ven su identidad desdibujada. En la nota 60 se rompe la ficción con humor. “¿Quiénes hemos iniciado la presente monografía? ¡Si no lo supiéramos, quisiéramos saberlo!" (Lihn, 2013, p. 170). El actuar de los narradores y la manera en que se atropellan, desmonta frente al lector los mecanismos de la palabra que legitima. La orquesta de cristal está escrita atendiendo a la voz del loco abigarrado, ese que habla con incontinencia para desnudar la fragilidad del sistema y dar cuenta del vacío que nos determina.

\section{El kitsch como cuadro de época}

\section{(C) $(\Theta \odot \odot$}

La Revista Estudios es editada por la Universidad de Costa Rica y se distribuye bajo una Licencia Creative Commons Atribución-NoComercial-CompartirIgual 3.0 Costa Rica. Para más información envíe un mensaje a 
En La orquesta de cristal, el kitsch opera a nivel temático a través de la apropiación que el autor hace de elementos convencionales de la realidad. La novela se enfoca en los simulacros que emergen a partir de un evento grandilocuente financiado por un empresario norteamericano, cuyo impulso industrial se ampara en el capitalismo como dogma. El texto expone un elemento que para Lihn es crucial en los años de dictadura: la evasión en una sociedad del espectáculo.

Al kitsch se le asigna una carga negativa que lo vincula con la repetición, lo fútil y trivial, en otras palabras, el pseudoarte. Enrique Lihn en el año 1984 escribe en la revista Cauce un texto denominado "El seudo arte de la seudo cultura" en el cual caracteriza la estética que predomina dentro del arte oficial, durante los años de dictadura en Chile (1973 a 1990).

Lihn, en ese texto, habla de un proceso regresivo de aculturación. El kitsch durante los años de gobierno de Augusto Pinochet entra a dominar todas las esferas del arte y la vida pública. Las condiciones de producción y difusión de las obras artísticas en Chile, no sólo las literarias, fueron de censura, marginación, autocensura y proselitismo, lo cual terminó por acrecentar la brecha entre la población y el arte.

El vacío que se produce en el campo cultural es llenado con divertimentos destinados a crear una masa acrítica. Lihn señala en sus crónicas, que algunos de estos mecanismos claramente eran propiciados por el gobierno. Simulacros como el Festival de Viña del Mar y el auge de la ciudad comercial en Santiago son provocados, mientras que otros surgen de manera espontánea debido a la sociosis creciente y la configuración de un espacio de socialización dominado por las industrias del espectáculo. Enrique Lihn expone:

Lo que la dictadura militar ha auspiciado en un supuesto campo cultural o lo que ha surgido como efectos de aquella, a partir del "frío mundo de los negocios"- el arte como negocio, el arte y la industria- si no es basura artística declarada tiene mucho de bluff y ya se empieza a percibir como una producción inflacionaria, políticamente sospechosa (Lihn, 1984, p. 38).

\section{(c) (1) 8 ()}

La Revista Estudios es editada por la Universidad de Costa Rica y se distribuye bajo una Licencia Creative Commons Atribución-NoComercial-CompartirIgual 3.0 Costa Rica. Para más información envíe un mensaje a 
La preocupación de Enrique Lihn por las condiciones de censura, las formas de producción artística, el arte comprometido y panfletario, el espectáculo y la cultura basura, además del rol que toca al intelectual, termina por modificar de manera radical su obra. En este contexto el autor publica La orquesta de cristal. En la novela, espectadores de todo el mundo se congregan ante la maravilla que representa the cristal orchestra y Roberto Albornoz narra su "experiencia audiovisual" para El Mercurio de Valparaíso. Es quizás esta primera aproximación cronística la que abrirá la puerta al simulacro que devendrá, puesto que el hombre, al no haber percibido nada debe escribir un texto que se centre en situaciones alrededor del evento, tal como el edificio suntuoso, los invitados, el aire de progreso, la riqueza cultural que se vive en París; e incluso en extensos devaneos sobre la música invocando a Wagner y su idea del arte puro. Sin embargo, en un diálogo epistolar con su amigo Pompifier, se nota como Albornoz se ve traicionado por su propia retórica:

Nos referimos a Roland de Glatigny, autor de la sinfonía Amor Absoluto, a cuyo estreno exclusivo asistimos y no asistimos el pasado 20 de abril del primer año del siglo veinte. Posiblemente, o así queremos creerlo, sin fundamentos ni tan siquiera en el testimonio de nuestros sentidos y en particular del sentido artístico (Lihn, 2013, p. 28).

Lo primordial es el uso que Lihn da a dos temas convencionales: el espectáculo de masas y su efecto persuasivo sobre un público adiestrado y acrítico, debido a la influencia de voces que sustentan la autoridad de hechos a través de medios oficiales, incluso si éstos sólo encubren el horror y la violencia de una sociedad en crisis.

A nivel de estructura, el kitsch opera en la edificación de la atmósfera en la cual se sitúa La orquesta de cristal. Nos referimos a la etapa ornamental, tal como Abraham Moles la describe en El Kitsch: El arte de la felicidad. El kitsch ornamental está destinado a la decoración excesiva y la acumulación de objetos de naturaleza 
disímil y desentonantes unos con otros. La descripción que Albornoz entrega en su crónica de La Casa de los Cuatro Vientos es representativa de estas ambientaciones afectadas por el kitsch burgués:

Nada quiero decir del encanto que significa pasar sin transición desde el boudoir auténticamente versallesco al género gótico de una sala de armas, para acceder luego a una habitación de la Alhambra de Granada, a un comedor del Renacimiento, a un baño turco. Acariciaríamos esas barandillas sobre las cuales bajan dando volteretas furias desnudas y hechizadas (Lihn, 2013, p. 26).

El kitsch también nos presenta al interior de la novela, un cambio en el gusto ciudadano. Las convenciones que determinan la relación entre sujetos y el placer que proporciona el consumo, van mutando acorde a los nuevos medios y las formas discursivas que estas tecnologías promueven. Las crónicas que se suceden de 1900 a 1915, nos presentan con fastuosidad un kitsch de acumulación, privilegiando el gusto burgués y los espacios ornamentados. En la segunda mitad del libro, aparece otra forma de kitsch, el cual Abraham Moles reconoce como propio de las sociedades de consumo. En esta modalidad el motor es la compra compulsiva. Este cambio en el estilo de escritura, la novela lo refleja por medio de la figura de Gabriel Shaumard.

La crónica de este joven periodista rompe con el estilo de sus predecesores, y busca desarrollar nuevas formas de representar al mundo a través del folletín y la prensa de farándula. La obra describe el estilo de Shaumard como propio de una revista de espectáculos, lo cual va marcando el cambio en los intereses del público. El resultado es un magazine titulado Mudo como una Orquesta de Cristal, el cual se caracteriza por el uso de la fotografía y otros medios que delatan la reproductibilidad técnica de los objetos de arte. La publicación se centra en el escarnio al compositor Roland De Glatigny, como si fuese una estrella caída en desgracia por problemas con la ley y las drogas:

Numerosas fotografías ilustraban esa joya de los quioscos de los bulevares, esa curiosidad de las librerías de vanguardia. Primeramente la de un enmascarado que lleva sobre su capucha el sombrero del Tío Sam; luego la foto borrosa de un pasaporte

\section{(๑) $(\Theta \odot$}

La Revista Estudios es editada por la Universidad de Costa Rica y se distribuye bajo una Licencia Creative Commons Atribución-NoComercial-CompartirIgual 3.0 Costa Rica. Para más información envíe un mensaje a 
del autor de Amor Absoluto, que parece en ella un delincuente común estragado por la tisis (Lihn, 2013, pp. 64-65).

Este cambio de concepción del kitsch está marcado por la muerte de Charles Royce, inversionista que funda la orquesta de cristal. A partir de su deceso en 1916, el control de la empresa pasa del manejo que pudiese realizar un sujeto, amparado en su visión de la revolución industrial, a un sistema operado por una fundación impersonal, la cual mantiene su prestigio en base a un sistema de becas y el compromiso ineluctable que deben tener los beneficiados con respecto a la institución. Se producirá, entonces, un giro en las motivaciones que impulsan a los escritores, que a partir de 1916 emprenden investigaciones sobre la orquesta. Los nuevos redactores (ni siquiera nombrados) aparecen tan sólo como becarios de la Fundación $\mathrm{X}$ y actúan en virtud de una lógica inspirada por el sistema de consumo. El discurso de los becarios es técnico y se vale de medios como la litografía y la fotografía para generar la publicidad en torno a la orquesta de cristal. El sujeto desaparece ante la máquina, pues los redactores ya no están motivados por su ego y la autofiguración que consiguen con sus crónicas. La obra, por medio del kitsch, expone la evolución de las experiencias de consumo y su relación con los objetos, además de la respectiva transposición que los artistas hacen de la realidad al texto en un complejo cuadro de época.

\section{Humor conceptual: simulacros y metalepsis}

Lihn edifica La orquesta de cristal como una monografía, pero también la trabaja como un divertimento que pone en tensión el uso del habla vacía y el arte de la palabra, dando a entender que la obra que tenemos en nuestras manos funciona en

\section{(C) $(000$}

La Revista Estudios es editada por la Universidad de Costa Rica y se distribuye bajo una Licencia Creative Commons Atribución-NoComercial-CompartirIgual 3.0 Costa Rica. Para más información envíe un mensaje a 
complicidad con el simulacro cultural que el texto plantea a nivel de estructura y tema.

La novela es autoparódica y pone en evidencia su propio vacío, a través de los mismos procesos con que se va constituyendo. A fin de cuestionar la novela como género, La orquesta de cristal entraña pasajes metalépticos que señalan la fecha de la primera edición por Editorial Sudamericana y delatan a su autor, Enrique Lihn, como el último de los cronistas de the crystal orchestra, enmascarado tras el seudónimo de Heinrich von Linderhöfer: "El mismo individuo (nosotros) que escribió, en una época indeterminada y desde un lugar incierto, el preludio o la obertura de La orquesta de Cristal ¿no será el mismo que se finge otro, Heinrich von Linderhöfer, para engañar a los lectores?" (Lihn, 2013, p. 169).

La novela conmina al lector a poner en tensión la lógica de su época y dejar expuestos los simulacros culturales que le rodean. Un elemento esencial del humor conceptual radica en que La orquesta de cristal plantea su propia autodestrucción y posterior reinvención en una paradoja sin fin, pues las crónicas se extienden desde 1900 hasta 1942, año en que la orquesta es destruida por la Gestapo y también asesinado su último cronista, Heinrich von Linderhöfer:

Un pseudonovelista vienés, Heinrich von Linderhöfer, melómano y dado en exceso a la filosofía del psicoanálisis, escribió —también a modo de preludio de un comentario tan abstruso como oficioso- las páginas con que hemos iniciado la presente monografía, hasta llegar a la liberadora cita de la interpretación de Albornoz, presentada por el susodicho Linderhöfer como un divertimento anecdótico (Lihn, 2013, p. 79).

El narrador principal indica que Von Linderhöfer es el encargado del prefacio e inicio de la novela, por tanto, el objeto al que se alude como centro de la obra y el sujeto que enuncia ya no existen en 1976, año en que se presenta la primera edición que llega a manos del lector. Linderhöfer es planteado como un recurso de estilo, un personaje ficticio destinado a dar un final a la novela y actuar como dispositivo para engañar a los destinatarios del libro.

\section{(C) $(\Theta \Theta \odot$}

La Revista Estudios es editada por la Universidad de Costa Rica y se distribuye bajo una Licencia Creative Commons Atribución-NoComercial-CompartirIgual 3.0 Costa Rica. Para más información envíe un mensaje a 
La novela persiste en su falsedad y artificio en concordancia con la actitud de encubrimiento que promueven los cronistas/copistas. Linderhöfer, mientras narra su texto, señala una paradoja que evidencia la transhistoricidad de todo lo que expone, pues indica la posibilidad de adivinar retroactivamente. Algo que es imposible, ya que dicha tautología delata el tener un conocimiento previo de hechos que a fuerza se exponen como pasados durante el presente, a fin de validar ideologías futuras. Se trata de una operación similar a lo que Orwell señalaba en la distópica 1984: "EI que controla el pasado — decía el slogan del Partido— controla también el futuro. El que controla el presente, controla el pasado" (Orwell, 1971, p. 36). La referencia a Orwell se comunica con la última novela de Lihn, El arte de la palabra (1980), que presenta una región llamada Miranda, la cual se encuentra sumida en una dictadura perpetua.

Linderhöfer, en un acto burlesco y de desenmascaramiento de su propia condición de falsario, hace uso de sus artes adivinatorias y anticipa su muerte. El cronista señala que 30 años después de su deceso se publicará un libro titulado $\mathrm{La}$ orquesta de cristal. La fecha coincide con la primera edición de la novela de Lihn en Argentina: "Decidido a no hacer estos recuerdos a título personal, me niego el placer de las adivinaciones retroactivas. Es cierto que no adiviné el macabro final de este último capítulo de una historia que seguramente se optará por titular La Orquesta de Cristal" (Lihn, 2013, p, 86). Esto reafirma la falsedad de la cita: "Todos los elementos de esta orquesta —-primero y único ejemplar en su género—" (Lihn, 2013, p. 17) que sirve de umbral a todas las crónicas del libro, empezando por la de Albornoz escrita en 1900, durante el estreno de the crystal orchestra. Resulta virtualmente imposible que el cronista y espeleólogo chileno pudiese citar a comienzos de siglo algo que recién se escribió en 1941 y que además fue destruido junto a su autor. De cualquier modo, la cita está allí, dicha a comienzos de siglo y por eso se publica en 1976 en el mentado preludio que es puesto en conocimiento del lector. Esta paradoja reitera la calidad de simulacro de toda la obra, pero además persiste en la idea de transhistoricismo, evidenciando que el pasado es el futuro y

\section{(c) (i) (9) (2)}

La Revista Estudios es editada por la Universidad de Costa Rica y se distribuye bajo una Licencia Creative Commons Atribución-NoComercial-CompartirIgual 3.0 Costa Rica. Para más información envíe un mensaje a revistaestudios.eeg@ucr.ac.cr. 
que no hay discursividad original respecto a tema alguno, sino un eterno reciclaje ad infinitum de la cultura. La hiperrealidad que presenta la novela da cuenta de un tiempo que se difumina entre las grandes ideas que movilizan una historia circular, terminando por morderse su propia cola como un uróboro.

En cuanto a la escena que cierra la novela, hay que destacar dos formas de falseamiento y humor conceptual comunicadas con la violencia que entraña el acto de represión ejecutado por la Gestapo. Un lejano familiar de Franz Kafka, descrito como un chelista obeso, es el último músico en morir tras el ingreso de los agentes alemanes a La Casa de los Cuatro Vientos. La obra nos dice que el primo del escritor checo falsificó sus documentos migratorios y creó una identidad fraudulenta utilizando para ello a la orquesta de cristal (el máximo simulacro que la novela nos presenta). Valiéndose de las becas de la Fundación X, escapó de los campos de concentración y evitó la persecución en contra de los judíos. El tema de las falsificaciones, copias y pastiches entra en juego entonces con este primo. La destrucción de la orquesta pone fin al núcleo que sirve de órbita a todo un universo de falsedades. El familiar del autor de La metamorfosis resulta patético con una corporalidad situada en las antípodas de su "primo"; todo en él es exagerado, inflado, desde su instrumento hasta el peso y sus gruesos anteojos que poco le sirven para ver; de allí que la mirada del personaje se nos antoje difusa, abierta a la especulación y al falseamiento:

Todavía en el primer plano el señor Kafka entornaba los ojos agigantados por sus lentes, tratando de obtener el mismo efecto de su instrumento biconvexo en el sentido de la ampliación de las mágicas notas del preludio, abrazándolo y acariciándolo con movimientos del cuerpo entero y delicadas manipulaciones de virtuoso (Lihn, 2013, p. 96).

La escena final es un happening que desenmascara el vacío tras la retórica del poder y el arte oficial, pues el primo de Kafka, que encontrara en un simulacro su camino de escape del Nazismo, muere en el momento en que la orquesta es destruida. No es casual que aquello que desencadena la violencia sea la música de un teutón declaradamente antijudío. El que los artistas hayan sido obligados a tocar

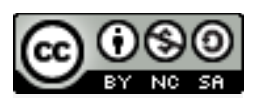

La Revista Estudios es editada por la Universidad de Costa Rica y se distribuye bajo una Licencia Creative Commons Atribución-NoComercial-CompartirIgual 3.0 Costa Rica. Para más información envíe un mensaje a 
Parsifal de Wagner es absurdo, pues si se tratase de la obra wagneriana o la sinfonía Amor absoluto, los instrumentos de the crystal orchestra se encuentran incapacitados para interpretar música alguna, debido a su inútil naturaleza. La imposibilidad se produce en múltiples niveles: a nivel vital, se concreta en la muerte de los músicos, a nivel artístico se verifica porque no se alcanza a tocar la pieza, dada la irrupción de las fuerzas armadas.

Por último, otro hecho que genera un espejo con las falsificaciones tiene que ver con la pieza Amor absoluto cuyo compositor, Roland De Glatigny, no guarda memoria de haberla realizado y que, al no haber sido tocada nunca, en verdad quizá tampoco existió. Amor absoluto obtiene al interior de la novela las interpretaciones más detalladas sobre su lírica en los trabajos hermenéuticos de Roberto Albornoz y el árabe Montazem. Albornoz es desenmascarado por el musulmán, en una crónica que detalla cómo la interpretación del crítico chileno es un plagio de la traducción de Franz Liszt del Lohengrin de Wagner:

Es un lánguido pastiche descorazonador de la traducción que hiciera Franz Liszt del Lohengrin de Wagner, citada por el autor de Las Flores del Mal en "Richard Wagner y Tannhäuser" y malamente disfrazado de algo que podría recordar un ballet de l'Olympia inspirado en algún tema de la antigua Grecia y protagonizado por una protegida de la celeste Venus Afrodita (Lihn, 2013, p. 39).

Este juego de copias y falsificaciones entramadas no queda allí, pues Montazem es descrito, por el narrador principal, como el traductor de Albornoz, su más grande detractor, pero también un plagiador de sus ideas. Todo lo que orbita en torno a the crystal orchestra y su sinfonía se edifica en base a citas mal hechas, traducciones mal atribuidas y pastiches que ocultan la ignorancia o mala fe del redactor de turno.

Hay que recalcar que la sinfonía de Roland De Glatigny, al igual que la orquesta, es prácticamente inexistente pues nunca ha sido tocada y el significado que le atribuyen ha sido generado por un plagiador que le copia textualmente a un intérprete de Wagner. La puesta en escena final, que nos relata Linderhöfer en su crónica, revela el acto supremo de falseamiento, ya que la evanescente lírica de

\section{(c) (i) (2)}

La Revista Estudios es editada por la Universidad de Costa Rica y se distribuye bajo una Licencia Creative Commons Atribución-NoComercial-CompartirIgual 3.0 Costa Rica. Para más información envíe un mensaje a 
Amor absoluto equivale a la obra de Wagner y el acto musical, de cualquier modo, no llegará a concretarse, dada la inutilidad de los instrumentos. La realidad cae al vacío precipitada por un acto represivo absurdo, el silenciamiento del silencio.

La orquesta de cristal por medio de actos autoparódicos, le recuerda al lector la falsedad del discurso que tiene en sus manos. El humor interviene la lógica que sustenta la retórica del poder y da cuenta de una atmósfera de apariencias y especulaciones, en que ideologías y pasajes de la historia se amparan en un amasijo de voces superpuestas que rodean al simulacro. La novela utiliza en su estructura juegos metalépticos que rompen la ficción y también pone en escena situaciones absurdas y paradójicas, las cuales reiteran las nociones de copia, pastiche y falsedad. Una importante es la seña editorial de la obra de Lihn, vía editorial Sudamericana y el lugar de publicación Argentina. Esta referencia la encontramos perdida en una carta injuriosa que uno de los personajes manda a la directiva de la Fundación X.

Esta presencia de lo extraliterario, en una obra que persevera en recordarnos su falsedad, extiende los efectos de lo hiperreal al mundo fuera de la novela. La orquesta de cristal como entramado de voces se inserta en una tradición, en un campo cultural y un género: el novelístico, con sus correspondientes productores, que en esos años también operan en base a ideologías y movimientos editoriales, como los autores del boom, y antes que ellos los poetas de las vanguardias, a los cuales Lihn busca desenmascarar, pues a ojos del autor, los cuadros de época y el bastardaje cultural de Latinoamérica se superponen en un eterno retorno.

Finalmente, La orquesta de cristal y sus personajes son una parodia del oficialismo intelectual y una revisión del artista como agente al servicio del gobierno. Chile durante la dictadura era un país contaminado por simulacros y odas al mal gusto, en el cual desfilaban artistas decorativos, condescendientes con el poder, monigotes y agentes culturales así como una crítica acostumbrada a pontificar desde el lugar seguro y cómodo de la prensa oficial. El medio conservador que tuvo el monopolio de la verdad durante esos años en Chile es el suplemento Artes y

\section{(c) (i) (2)}

La Revista Estudios es editada por la Universidad de Costa Rica y se distribuye bajo una Licencia Creative Commons Atribución-NoComercial-CompartirIgual 3.0 Costa Rica. Para más información envíe un mensaje a revistaestudios.eeg@ucr.ac.cr. 
Letras del Mercurio, mencionado en la novela, al ser el medio en el cual publica sus crónicas Roberto Albornoz.

Como un ejercicio metatextual y alegórico del horror vacui, La orquesta de cristal funciona como una: "opción táctica, la de incorporar al texto la censura, eludiéndola: la producción del contexto de un texto que pueda decirlo casi todo, sin aludir a casi nada, en el cual, elusión, alusión e ilusión (de ilusionismo) se identifican" (Lihn, 1996, p. 590).

La inteligencia de esta obra radica en la posibilidad que tiene el autor, para producir una novela acerca de la dictadura a vista y paciencia de los organismos represores, que no logran entender los procedimientos con que la obra se estructura. Por eso el carácter elusivo y a la vez alusivo. Las estrategias comunicativas que Enrique Lihn despliega son las mismas que el poder utiliza para deformar la realidad con sus disfraces. La novela se erige como acción contraliteraria y también como un artefacto que descompone los límites de la realidad y sus mecanismos de representación.

Enrique Lihn concibe su narrativa al margen de un tipo de escritura documental, la cual critica y reconoce como una preocupada de crear en Chile la gran novela sobre la dictadura, mientras que, en Latinoamérica, la prosa que considera agotada ha buscado apropiarse temáticamente de las crisis que han generado los gobiernos de facto durante esos años. Para Lihn aun cuando al término realismo se le agregué el adjetivo mágico, persiste el gesto histórico y representativo.

Los escritores que el autor reconoce como antagonistas, sólo han rascado la superficie evidenciando el horror que otros vivieron: "No escribir un poema sangriento que lo tienes que esconder bajo un colchón y mandarlo a Canadá, y agarrarte la cabeza a dos manos si llegan a publicarlo con tu nombre, sino que hacer otro tipo de literatura, desafiante, que hablara desde el lenguaje del poder, en forma mimética" (Lihn citado en Foxley, 1988, p. 4).

En un texto de 1979 titulado "Intraliteratura", Lihn señala que frente a esos escritores que se han empecinado en generar una representación objetiva de lo que

\section{(c) (i) (2)}

La Revista Estudios es editada por la Universidad de Costa Rica y se distribuye bajo una Licencia Creative Commons Atribución-NoComercial-CompartirIgual 3.0 Costa Rica. Para más información envíe un mensaje a 
entendemos por realidad, hay otros autores -entre los cuales se incluye -que han persistido en verosimilizar lo impensado, desnudando el carácter artificial del arte.

\section{Bibliografía}

Cánovas, Rodrigo (1986). Lihn, Zurita, Ictus, Radrigán: Literatura chilena y experiencia autoritaria. Santiago: Serie Libros FLACSO-Chile.

Coddou, Marcelo (1978). A la verdad por lo imaginario. Entrevista con Enrique Lihn. Texto Crítico (11), 136-157.

Diez, Luis. A. (1980): La narrativa agenérica de Enrique Lihn (Segunda parte). Hispanic Journal, 1 (2), 91-99.

Foxley, Ana María (1988, 05, 29): La imaginación es una manera de enmendarle la plana a la realidad. La Época, pp. 4-5.

Gómez, José (1981). Enrique Lihn y el arte de las palabras vacías. Periódico de Catalunya (714), 6-7.

Lastra, Pedro (1980). Conversaciones con Enrique Lihn. México: Universidad Veracruzana.

Libertella, Héctor (1990). Ensayos o pruebas sobre una red hermética. Buenos Aires: Grupo Editor Latinoamericano.

- (1993). Las sagradas escrituras. Buenos Aires: Sudamericana.

Lihn, Enrique (1980). El arte de la palabra. Barcelona: Editorial Pomaire.

_ (1984). El seudo arte de la seudo cultura. Cauce (8), 38-39.

- (1996). El circo en llamas. Santiago: Lom.

- (2011). Doce años de escritura en todos los géneros. Anales de Literatura Chilena (16), 183-201.

- (2013). La Orquesta de Cristal. Santiago de Chile: Hueders.

Moles, Abraham (1990). El Kitsch: el arte de la felicidad, trad. de Josefina Ludmer. Barcelona: Paidós.

Orwell, George (1971). 1984, trad. de Rafael Vázquez Zamora. Barcelona: Salvat.

\section{(c) (i) (2)}

La Revista Estudios es editada por la Universidad de Costa Rica y se distribuye bajo una Licencia Creative Commons Atribución-NoComercial-CompartirIgual 3.0 Costa Rica. Para más información envíe un mensaje a revistaestudios.eeg@ucr.ac.cr. 